\title{
NORMATIVE VALUES FOR TISSUE DOPPLER IMAGING (TDI) VELOCITIES IN PRETERM
} INFANTS

\author{
M.S. Saleemi ${ }^{1}$, O. Franklin ${ }^{2}$, J.D. Corcoran ${ }^{1}$ \\ ${ }^{1}$ Paediatrics, Rotunda Hospital, ${ }^{2}$ Cardiology, Our Ladys Hospital for Sick Children, Crumulin, Dublin, \\ Ireland
}

Background: Tissue Doppler imaging (TDI) is potentially useful measure of myocardial function in newborn infants but little is known about normal values at various gestations.

Aim: We evaluated myocardial contractility by TDI at birth and different postnatal ages, in preterm infants.

Method: Preterm infants $<35$ weeks of gestation were divided into group-1 (24-27 weeks gestation), group2 (28-31 weeks gestation) and group-3 (32-35 weeks gestation). All infants with severe congenital malformations and intercurrent illnesses were excluded. Echocardiograms were performed by a single observer at $<48$ hours, week 2 and week 4 of life. The statistical procedure used was repeated-measures ANOVA.

Results: There was a gradual increase in left ventricular TDI velocity in systole (LTDI S) over 4 weeks, 12\% in group-1, 26\% in group-2 and 31\% in group-3. LTDI S increased with increasing gestational age with a significant difference between group 1 and $3(p=.005)$ but not between group 1 and 2 or between 2 and 3. We observed a significant between-subjects effect of different gestational age groups $(p=.007)$ and a significant within subject effect $(\mathrm{p}<.001)$ as postnatal age increases.

Conclusions: LTDI $\mathrm{S}$ is higher in less preterm infants and increases over time in all preterm infants. However extremely preterm infants have a lesser increase than more mature infants.

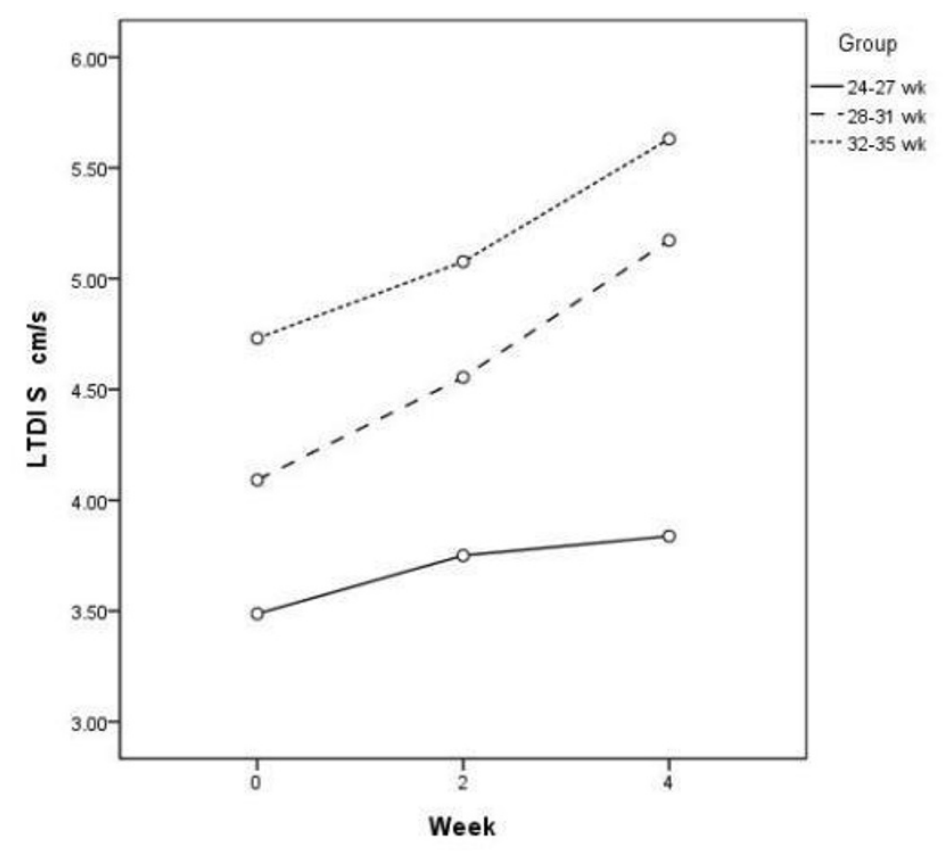

[neo heart] 